\title{
ANALISIS KEBUTUHAN FUNGSI DAN EXPRESI BAHASA UNTUK RESEPSIONIS DI HOTEL BERBINTANG DI BALI
}

\author{
A.A.Ngr. Yudha M. Mahardika \\ Yudhamartin_mph@yahoo.com \\ S3 Pendidikan Bahasa Inggris, Fakultas Sastra, Universitas Negeri Malang \\ Manajemen, Fakultas Ekonomi, Universitas Pendidikan Ganesha
}

\begin{abstract}
Abstrak
Penelitian ini bertujuan untuk menganalisis kebutuhan fungsi dan ekspresi bahasa yang dibutuhkan oleh seorang Penerima tamu (resepsionis) di hotel-hotel berbintang di Bali. Penelitian ini berjenis penelitian analisis kebutuhan. Untuk mendapatkan informasi yang dibutuhkan, observasi, wawancara, dan dokumentasi dilakukan. Informasi yang dikumpulkan kemudian dianalisis secara deskriptif. Dari penelitian diperoleh beberapa temuan (1) Fungsi-fungsi bahasa yang muncul disesuaikan dengan 4 tugas utama resepsionis yaitu sebelum kedatangan, saat kedatangan, saat tamu menginap, dan keberangkatan. Masing-masing tugas tersebut terbagi-lagi menjadi beberapa aktivitas sesuai dengan SOP. (2) Ekspresi-ekspresi berbahasa yang muncul untuk masing-masing fungsi bahasa bervariasi disesuaikan dengan karakteristik hotel serta hubungan keakraban dengan tamu. Ekspresi-ekspresi bahasa yang muncul dipergunakan secara spesifik hanya di ranah kantor depan oleh para resepsionis. Dari hasil penelitian, dibutuhkan penelitian lanjutan dalam hal pengembangan silabus dan perbaikan proses pembelajaran yang didasarkan atas hasil analisis kebutuhan.
\end{abstract}

Kata-Kata Kunci: Analisis kebutuhan, Fungsi dan ekspresi bahasa, Resepsionis

\section{PENDAHULUAN}

Jurusan Perhotelan, yang merupakan salah satu jurusan yang memfokuskan diri dalam menciptakan tenaga profesional dalam bidang perhotelan, menyadari pentingnya ketrampilan berbahasa Inggris bagi mahasiswanya kelak. Sayangnya, berdasarkan hasil pengamatan awal, silabus mata kuliah tersebut masih disusun berdasarkan atas kompilasi buku dan bukan didasarkan atas analisis kebutuhan seperti yang seharusnya dilakukan dalam pengajaran bahasa Inggris Profesi (English for Specific Purposes/ESP).

Berdasarkan berbagai hasil penelitian mengenai pengembangan kurikulum (misal, Ratminingsih, dkk., 2012; Koyan, dkk., 2010; Mahardika, 2014; Ratminingsih, dkk., 2018) ditunjukkan bahwa gambaran tentang skill, fungsi, dan expresi bahasa di dalam silabus pengajaran Bahasa Inggris Profesi cenderung belum menyesuaikan dengan kebutuhan pasar dan mahasiswa. Saran dari hasil penelitian tersebut adalah melakukan analisis kebutuhan untuk semua mata kuliah Bahasa Inggris Profesi.

Melihat saran dari hasil penelitian tersebut, maka dirasa perlu untuk melakukan penelitian lanjutan mengenai analisis kebutuhan untuk mata kuliah Bahasa Inggris Profesi. Untuk penelitian kali ini, Bahasa Inggris Profesi Kantor Depan dipilih sebagai bahan kajian. Mata kuliah ini dipilih karena selain merupakan departemen di hotel yang cukup sering dijadikan sasaran Praktek Kerja Lapangan (PKL), bagian Kantor Depan juga merupakan departemen di hotel yang paling sering mempergunakan bahasa Inggris. Sehingga kebutuhan akan bahasa Inggris Kantor Depan yang sesuai dengan kebutuhan pasar dirasa cukup mendesak di jurusan Perhotelan. Berkaca dari penelitian sebelumnya, objek penelitian yang dicari adalah fungsi dan ekspresi bahasa yang dibutuhkan di hotel. Fungsi dan ekspresi bahasa yang dicari diperoleh melalui hasil observasi langsung ke lapangan, wawancara dengan pihak manajemen, serta pengumpulan dokumen seperti SOP 
(Standard Operational Procedure) dan Training Activity Program. Penelitian kali ini juga akan menerapkan metodologi penelitian yang sejenis yaitu menganalisis kebutuhan fungsi dan ekspresi bahasa yang dibutuhkan di Kantor Depan (utamanya Resepsionis) melalui proses observasi, wawancara dan pengumpulan dokumen di hotel berbintang di Bali.

Terdapat beberapa definisi berbeda tentang analisi kebutuhan dipaparkan oleh para ahli. Richards (1987) mendefinisikan analisis kebutuhan sebagai proses determinasi kebutuhan berbahasa yang dibutuhkan oleh seorang atau sekelompok pelajar dan menyusun kebutuhan tersebut berdasarkan prioritasnya. Menurutnya, dengan mengetahui kebutuhan siswa maka pengajar dapat mengatur/memprogram materi atau silabus yang sesuai. Sedang, William and Swales (dalam Robinson, 1984) memandang analisis kebutuhan sebagai 'target-centered' yang mana terdapat usaha untukmengetahui tugas yang akan diemban dilapangan dan kemudian mendspesifikasikan skill, fungsi dan expresi bahasa apa yang diperlukan oleh siswa agar mampu melaksanakan pekerjaan tersebut dengan baik. Lebih lanjut, Munby (dalam Robinson, 1984) menyatakan bahwa analisis kebutuhan dilakukan untuk mengetahui situasi saat ini (Present Situation) dan situasi target (Target Situation) sehingga nantinya siswa mampu menggunakan bahasa Inggris untuk membantu tugas dan aktifitas dalam pekerjaannya. Perbedaan definisi di atas tidaklah mengubah fokus dari analisis kebutuhan yaitu siswa dan tempatnya bekerja.

Analisis kebutuhan sangat penting dalam upaya mengetahui kebutuhan siswa. Mahasiswa umumnya sudah dewasa dan sadar akan diri dan tujuannya. Oleh sebab itu pembelajaran sebaiknya lebih ditujukan kepada siswa (learner-centered) (Robinson, 1984). Selain mengetahui kebutuhan siswa, kebutuhan pasar juga patut diperhitungkan. Jenis pekerjaan yang berbeda menuntut tugas yang berbeda sehingga kemungkinan level kemampuan berbahasa yang diharapkan juga berbeda. Dengan melakukan analisis kebutuhan dapat dilihat tugas yang diemban serta tuntutan kemampuan berbahasa yang diinginkan. Dengan adanya gambaran tentang tujuan belajar siswa, tugas-tugas yang diemban dalam pekerjaan dan kemampuan berbahasa yang diharapkan, yang didapat dari analisis kebutuhan, program pengajaran pun dapat dilaksanakan ddan silabus dapat pula tersusun.

Sebagai langkah awal dalam penyusunan silabus English for Front Office, dibutuhkan gambaran tentang tugas dan kemampuan berbahasa yang dibutuhkan dalam pekerjaan tersebut (dalam penelitian ini sudah mengkhusus pada Resepsionis). Salah satu jenis silabus yang umum dipergunakan dalam pengajaran bahasa Inggris profesi adalah functional syllabus yang memuat fungsi dan expresi bahasa yang diperlukan dalam pekerjaan tersebut. Oleh karena itu, yang patut untuk dibahas lebih lanjut adalah tentang apa itu fungsi dan expresi bahasa.

Fungsi bahasa adalah segala sesuatu yang dilakukan oleh pembicara dengan bahasa dalam komunikasi (Savignon, 1983). Contoh yang diberikan adalah: memberi salam (Greeting), memberi perintah (Giving Command), memberikan informasi (Giving Information), dan sebagainya. Sedang, Expresi bahasa adalah ujaran-ujaran yang diexpresikan pada konteks yang tepat untuk suatu fungsi tertentu (Van Ek, 1977). Contoh expresi bahasa memberi salam untuk pagi hari adalah 'Good Morning'.

Savignon (1983) lebih lanjut menyatakan bahwa memahami dan menguasai fungsi dan expresi bahasa akan sangat membantu dalam kesuksesan berkomunikasi. Hal ini disebabkan karena fungsi dan expresi bahasa yang diujarkan tidak semata-mata memfokuskan pada ketepatan gramatikal tapi juga pada 
'uttarances of communication' yang mana pengajaran seperti ini dirasa lebih bermakna, menyatu, mudah dipahami dan sesuai dengan konteks.

Tugas utama seorang resepsionis di hotel berbintang di Bali distandarkan oleh masing-masing hotel yang dituangkan dalam SOP (lihat lampiran). Secara umum tugas yang muncul relatif sama. Perbedaan yang muncul dipengaruhi oleh kebijakan hotel, situasi dan kondisi yang ada serta hubungan kedekatan dengan tamu. Terdapat 4 tugas/aktifitas resepsonis di hotel berbintang di Bali, yaitu Persiapan Kedatangan, Kedatangan, Saat Tamu Tinggal, dan Keberangkatan. Di setiap proses terdapat beberapa tugas yang harus dijalankan oleh seorang resepsionis. Aktivitas utama adalah berinteraksi/berkomunikasi dengan tamu. Implikasi dari hasil penelitian ini adalah Jurusan Perhotelan Undisha sebagai lembaga yang mempersiapkan tenaga siap pakai di bidang perhtelan (dalam hal ini resepsionis), haruslah bisa memberikan informasi kepada mahasiswanya mengenai fungsi dan ekspresi bahasa yang dibutuhkan dalam melakukan pelayanan sebagai resepsionis serta memberikan kesempatan yang seluas-luasnya untuk melakukan komunikasi dalam bahasa Inggris terutama yang terkait dengan tugasnya sebagai resepsionis. Mahasiswa juga harus disiapkan untuk mampu beradaptasi dengan berbagai perbedaan yang muncul dalam pelayanan yang ada di masing-masing hotel.

Di dalam keempat tugas/aktifitas yang disebutkan diatas, terdapat fungsi dan ekspresi berbahasa yang dibutuhkan oleh resepsionis. Kesempatan untuk berinteraksi dengan tamu lebih banyak ditemukan saat proses Kedatangan dan Keberangkatan, sehingga kedua proses inilah yang akan difokuskan. Walaupun terdapat fungsi-fungsi bahasa yang sama dalam proses Kedatangan dan Keberangkatan, akan tetapi, ekspresi-

\section{PEMBAHASAN}

Setelah dilakukan analisis data sesuai dengan prosedur yang telah dipaparkan sebelumnya, maka penulis merangkum hasilnya dalam tabel berikut: ekspresi bahasa yang dipergunakan bisa jadi berbeda. Diambil contoh saat menyapa tamu. Jika pada saat kedatangan salam yang dipergunakan adalah "Om Swastyastu. Good morning. Welcome to our hotel, how may I assist you?", pada saat keberangkatan penyebutan nama dianjurkan "Good afternoon, Mr. Martin. How may I help you?". Hal ini dikarenakan resepsionis diwajibkan untuk menghafalkan wajah dan nama tamu yang menginapdi hotel. walaupun demikian, di beberapa hotel penggunaan Sir/Madam masih bisa dimaklumi.

Ekspresi-ekspresi bahasa yang dipergunakan biasanya disesuaikan didasarkan atas berbagai faktor seperti, kebijakan hotel serta tingkat keakraban dengan tamu. Biasanya, ekspresi-ekspresi bahasa Formal yang dipergunakan, dimana penggunaan ujaran 'May' dan 'Could' paling sering diamati. Dari hasil dokumentasi, observasi dan wawancara juga diketahui bahwa ekspresi-ekspresi bahasa yang dipergunakan secara spesifik hanya dipergunakan di ranah kantor depan oleh para resepsionis. Dicontohkan, ekspresi "Good Morning, welcome to our hotel. How may I assist you?" hampir tidak mungkin ditemukan dalam percakapan sehari-hari pada ranah yang lain. Tidak mungkin ujaran tersebut akan ditemui pada percakapan antar teman sekelas dalam situasi kelas (kecuali untuk aktivitas role play). Ujaran "If you need anything, please feel free to dial the front desk" juga hampir tidak mungkin diungkapkan oleh seorang dosen kepada mahasiswanya dalam keseharian. Ekspresi-ekspresi berbahasa tersebut tidak jamak ditemukan dikeseharian. hal ini sesuai dengan hasil temuan dari Hutchinson dan Waters (1987) yang menyatakan bahwa "the language we 
speak and write varies considerably, and in a number of different ways, from one context to another. Implikasinya adalah ekspresi-ekspresi tersebut harus dilatihkan, dibiasakan. Kemampuan bahasa Inggris umum tentunya belumlah cukup.

Dari hasil wawancara, diketahui bahwa resepsionis merupakan pekerjaan yang sangat penting di hotel. merekalah yang memberikan kesan awal dan akhir bagi para tamu. Oleh karena itu seorang resepsionis harus mampu mewakili hotel dalam memberikan kesan positifkepada tamu, melalui pemberian pelayanan yang baik secara profesional. Dari hasil temuan juga diketahui bahwa terdapat sesuatu selain ketrampilan berbahasa yang harus bisa dimiliki oleh seorang resepsionis. Terdapat kebutuhan akan ketrampilan pelayanan dan ketrampilan lunak (softskill), yang mana keduanya dianggap sama pentingnya dengan ketrampilan berbahasa. Pemahaman budaya juga dianggap penting walaupun tidak menjadi kewajiban. Hasil penelitian ini hampir sama dengan penelitian Laborda yang menyatakan bahwa terdapat kebutuhan akan pemahaman sosio-kultural, ketrampilan interpersonal, dan juga ketrampilan berbahasa. Dalam ketrampilan pelayanan (serving skill) termasuk didalamnya ketrampilan mengatasi keluhan/masalah juga harus dimiliki oleh para resepsionis. Selain itu, kerapian dan kebersihan dalam berpakaian menjadi penting dan distadarkan oleh semua hotel serta dituangkan ke dalam SOP tersendiri (lihat lampiran). Dalam SOP juga tercantum berbagai standar saat melakukan interaksi dengan tamu seperti senyum, kontak mata, postur tubuh, dan salam.

Implikasinya adalah bahwa mahasiswa jurusan Perhotelan haruslah dikondisikan untuk memiliki ketrampilan pelayanan ini dan juga ketrampilan berbahasa untuk bisa bekerja dengan baik sebagai resepsionis. Perkuliahan Bahasa Inggris Kator Depan harus mampu memberikan kesempatan mahasiswa untuk melakukan praktek pelayanan sebagai resepsionis melalui aktifitas role-play. Hal ini tentunya perlu didukung dengan adanya sarana dan prasarana yang memadai, seperti lab perhotelan.

Namun, perlu dijadikan catatan bahwa perkuliahan Bahasa Inggris Kantor Depan tidak malah berubah menjadi kelas untuk latihan ketrampilan melayani. Tujuan utamanya haruslah tetap melatihkan ketrampilan berbahasa Inggris untuk resepsionis. Seperti yang diungkapkan oleh Crocker (1981, in Astika, 1999) bahwa "...ESP concerns on 'something outside the language using the medium of language' i.e. the language mastery which is useful to smoothen the works". Hal ini berarti bahwa perkuliahan Bahasa Inggris Kantor Depan harus fokus kepada pelatihan ketrampilan berbahasa seperti pelatihan kosakata dan ekspresi bahasa, memberi salam, enawarkan bantuan, meberikan informasi, menyelesaikan masalah pembayaran, serta ketrampilan berbahasa lain pada konteks departemen Kantor Depan.

Ketrampilan lunak (soft-skills) juga harus dimiliki. Seorang resepsionis tidak hanya harus mampu berkomunikasi dengan lancar menggunakan bahasa Inggris, namun juga mampu menunjukkan karakteristik empati, jujur, aktif dalam mendengarkan, serta tulus dalam pelayanan selama proses komunikasi berlangsung. Ketrampilan non-verbal seperti melakukan kontak mata dan memberikan senyum yang tulus juga harus dimiliki. Sebagai konsekuensinya, perkuliahan Bahasa Inggris Kantor Depan haruslah mampu mengakomodasi kebutuhan tersebut melalui aktivitasaktivitas yang mampu mengesplorasi ketrampilan tersebut. Terdapat opini bahwa ketrampilan semacam ini tidak bisa diajarkan (Kavaliauskiene, 2002). Namun, sudah menjadi kewajiban bagi dosen pengajar untuk menunjukkan dan menekankan ketrampilan-ketrampilan tersebut melalui sebuah pembiasaan (habit 
formation). Pembiasaan ini haruslah disusun dengan sedemikian rupa sehingga mampu dipahami dan bisa dilaksanakan oleh mahasiswa. Dibutuhkan usaha ekstra yang berkelanjutan dan dengan cara yang implisit untuk bisa menanamkan ketrampilan lunak ini.

\section{KESIMPULAN}

Dari hasil penelitian ini dapat disarankan beberapa hal sebagai berikut:

a. Perbedaan fungsi dan ekspresi berbahasa yang ada di tiap-tiap hotel haruslah dipahami oleh mahasiswa. Oleh karena itu disarankan kepada jurusan Perhotelan untuk mampu memfasilitasi mahasiswa untuk mampu melatihkan fungsi dan ekspresi berbahasa yang dibutuhkan.

b. Terdapat kebutuhan akan ketrampilan selain ketrampilan berbahasa, seperti ketrampilan pelayanan, ketrampilan lunak (soft-skill), dan juga pemahaman budaya (Cross-culture Understanding/CCU). Ketrampilanketrampilan ini juga harus dilatihkan dalam perkuliahan Bahasa Inggris Kantor Depan melalui sebuah pembiasaan yang diselipkan secara implisit melalui aktivitas-aktivitas pembelajaran yang mampu mengakomodasi kebutuhan tersebut.

c. Dibutuhkan sebuah penelitian lanjutan untuk mampu menindaklanjuti hasil penelitian ini. Diperlukan sebuah penelitian pengembangan silabus yang didasarkan atas hasil analisis kebutuhan serta pengembangan buku ajar yang didasarkan atas hasil penelitian-penelitian tersebut.

d. Penelitian-penelitian sejenis juga perlu dikembangkan untuk menganalisis kebutuhan akan kebutuhan berbahasa yang dibutuhkan di departemen lain selain Kantor Depan, sepertiTata Graha, Reservasi, Sales dan Kitchen.

\section{DAFTAR PUSTAKA}

Astika, Gusti. 1999. The Role of Needs Analysis in English for Specific Purposes. TEFLIN Journal volume $X$ number 1 August 1999. Badan Kerjasam Antar Jurusan Bahasa dan Sastra Inggris di Indonesia.

Hutchinson, T. \& A. Waters. 1987. English for Specific Purposes: A Learning-Centered Approach. Cambridge: Cambridge University Press.

Koyan, dkk. 2012. Pengembangan Kurrikulum and Perangkat Pembelajaran Bahasa Inggris Berwawasan Budaya Lokal bagi SMK Pariwisata. Aporan Penelitian tidak diterbitkan. Denpasar: Universitas Pendidikan Ganesha

Mahardika, AANY Martin. 2014. Pengembangan Model Pembelajaran Cooperative Learning Untuk Mata Kuliah English For Food And Beverage Di Jurusan Perhotelan Undiksha. Prosiding, Seminar Nasional Riset Inovatif II, tahun 2014.

Ratminingsih, dkk. 2018. English for Tour Guide: A Need Analysis of a Contextual-Based Language Teaching.SHS Web of Conferences, vol 12, p. 12.

Ratminingsih, dkk. 2012. Pengembangan Kurikulum dan Perangkat Pembelajaran Bahasa Inggris Berwawasan Budaya Lokal bagi SMK Pariwisa ta untuk Menunjang Pengembangan Ekonomi Kreatif di Sentra Pariwisata Bali. Laporan Akhir Penelitian MP3EI 
Reforma: Jurnal Pendidikan dan Pembelajaran Vol. 8 No. 1 (2019) p-ISSN: 2503-1228; e-ISSN: 2621-4172

Richards, 1989. American Breakthrough. Oxford: Oxford University Press.

Robinson, Pauline C. 1984. ESP: The Present Condition. Oxford: Pergamon Press

Savignon, Sandra.1983. Communicative Competence Theory and Clasrrom Practice and Content in Second Language Learning. New York: Addison Westly Publishing Company, Inc.
Stapa, Siti H. 2006. ESP Students' Learning Preferences: Are the Teacher Aware? Online Journal for Teacher(ISSN 1682-3257: http://www.espworld.info/Articles_9/StapaESPworld.htm, diakses Agustus 2018)

Van ek. 1977. The Threshold Level for Modern Language Learning in Schools. USA: Longman Group Ltd 